Article

\title{
Structure and Stability of Iron Fluoride at High Pressure-Temperature and Implication for a New Reservoir of Fluorine in the Deep Earth
}

\author{
Yanhao Lin ${ }^{1,2, *}$, Qingyang $\mathrm{Hu}^{1, *}, \mathrm{Li} \mathrm{Zhu}^{2}$ (D) and Yue Meng ${ }^{3}$ \\ 1 Center for High Pressure Science and Technology Advanced Research, Shanghai 201203, China \\ 2 Earth and Planets Laboratory, Carnegie Institution for Science, Washington, DC 20015, USA; \\ lzhu@carnegiescience.edu \\ 3 HPCAT, X-ray Science Division, Argonne National Laboratory, Lemont, IL 60439, USA; ymeng@anl.gov \\ * Correspondence: yhlin@carnegiescience.edu (Y.L.); qingyang.hu@hpstar.ac.cn (Q.H.)
}

Received: 16 August 2020; Accepted: 4 September 2020; Published: 5 September 2020

\begin{abstract}
Fluorine (F) is the most abundant halogen in the bulk silicate Earth. F plays an important role in geochemical and biological systems, but its abundance and distribution in the terrestrial mantle are still unclear. Recent studies suggested that $\mathrm{F}$ reservoirs in the deep mantle are potentially hosted in terrestrial oxide minerals, especially in aluminous bridgmanite. However, the knowledge about the formation and stability field of fluoride in the Earth's interior is rare. In this study, we combine in situ laser-heated diamond anvil cell, synchrotron X-ray diffraction, and first-principles structure search to show that a new tetragonal structure of $\mathrm{FeF}_{3}$ is stable at pressures of $78-130 \mathrm{GPa}$ and temperatures up to $\sim 1900 \mathrm{~K}$. Simulation predicted the tetragonal phase takes a much denser structure due to the rotation of $\mathrm{FeF}_{6}$ octahedral units. The equations of states of tetragonal $\mathrm{FeF}_{3}$ are determined by experiment and verified by simulation. Our results indicate that $\mathrm{FeF}_{3}$ can be a potential key phase for storing F in the Earth's lower mantle and may explain some mantle-derived magma with high F concentration.
\end{abstract}

Keywords: iron fluoride; Earth's lower mantle; laser-heated diamond anvil cell; high pressuretemperature

\section{Introduction}

The halogens ( $\mathrm{F}, \mathrm{Cl}, \mathrm{Br}$, and I) are important volatile elements but their behaviors are much less constrained than their peer volatile elements, such as carbon and hydrogen. Here, we focus on fluorine (F), which is the most abundant and lightest halogen in the Earth's mantle [1]. Previous studies show that the presence of $\mathrm{F}$ in the mantle can significantly affect the chemical and physical properties of the silicate melt, including magma viscosity [2] and melting temperature [3].

The F content in the bulk silicate Earth (BSE) is estimated to be $\sim 25 \mathrm{ppm}$ based on concentrations measured in natural basalts and peridotites, which is lower than that in carbonaceous chondrites $(\sim 60 \mathrm{ppm})$ [1]. Previous experiments observed that some mantle-derived magma (e.g., oceanic island basalt (OIB)) contains $~ 55$ ppm of F [4,5], which is higher than the value of BSE. Moreover, Koga and Rose-Koga [6] summarized that $\mathrm{F}$ has surprisingly lower content than its neighboring elements like $\mathrm{C}, \mathrm{N}, \mathrm{O}, \mathrm{Ne}$, and $\mathrm{Na}$ based on atomic numbers and the depletion of $\mathrm{F}$ might be stored in deep Earth. All the above statements indicate that the distribution of $\mathrm{F}$ might be heterogeneous and there could be a potential $\mathrm{F}$ reservoir in the deep mantle. This hypothesis was implied by some terrestrial oxide mineral samples, which can contain several thousand ppm F [7-12]. There are also known F-containing minerals in the lower mantle, such as oskarssonite $\mathrm{AlF}_{3}$, parascandolaite $\mathrm{KMgF}_{3}$, and a new, unnamed 
fluoride, $(\mathrm{Ba}, \mathrm{Sr}) \mathrm{AlF}_{3}[13,14]$. Du et al. [15] predicted that the heavy halogens $(\mathrm{Cl}, \mathrm{Br}$, and I) can stay in the Earth's core through the formation of Fe-halides based on the first-principles structural searches up to $360 \mathrm{GPa}$. Since a large $\mathrm{Fe}^{3+}$ excess in the lower mantle can be created by the disproportionation of $\mathrm{Fe}^{2+}$ combined with removal of $\mathrm{Fe}^{0}$ droplets to the core $[16,17], \mathrm{FeF}_{3}$ could become an important $\mathrm{F}$ carrier in the deep mantle. Although an X-ray diffraction study on $\mathrm{FeF}_{3}$ up to $23 \mathrm{GPa}$ at room temperature has been performed [18], there is no study about $\mathrm{FeF}_{3}$ at the Earth's lower-mantle conditions. In this study, we investigate the structure and stability of $\mathrm{FeF}_{3}$ at high pressure and high temperature corresponding to the conditions from the middle to lowermost mantle (78-130 GPa and up to 1900 K).

\section{Methods}

Global structural optimization was performed using the CALYPSO (Crystal structure AnaLYsis by Particle Swarm Optimization) code $[19,20]$ with the particle swarm optimization algorithm, which has successfully predicted structures of various systems ranging from elements to binary and ternary compounds [21-23]. The total energy calculations were carried out using density functional theory within the Perdew-Burke-Ernzerhof (PBE) generalized gradient approximation [24] as implemented in the VASP (Vienna Ab initio Simulation Package) code [25]. We used projector augmented waves [26] with $3 s^{2} 3 p^{6} 3 d^{6} 4 s^{2}$ and $2 s^{2} 2 p^{5}$ as valence electrons for Fe and $\mathrm{F}$ atoms, respectively. The use of a plane-wave kinetic energy cutoff of $550 \mathrm{eV}$ and adoption of dense k-point sampling were shown to give excellent convergence of total energies. To determine the dynamical stability of the studied structures, we performed phonon calculations by using the finite displacement approach, as implemented in the PHONOPY code [27].

A mixture of $\mathrm{FeF}_{3}$ (amorphous, $1 \mu \mathrm{m}$ grain size, purity 99.999\%) and Au powder was ground in a ball mill for $2 \mathrm{~h}$. The mixture of the amorphous $\mathrm{FeF}_{3}$ and $\mathrm{Au}$ powder was cold pressed into a thin foil about $\sim 30 \times 30 \mu \mathrm{m}^{2}$ in size and $\sim 10 \mu \mathrm{m}$ in thickness. The sample foil was loaded in a $55 \mu \mathrm{m}$ diameter hole in a rhenium gasket indented by diamond anvils with $100 \mu \mathrm{m}$ culet diameter in a symmetric Mao-Bell diamond anvil cell [28]. Neon gas was used as pressure medium in our experiments. Samples were heated in a double-sided laser-heated diamond anvil cell (DAC) [29] and examined in situ at high pressures and temperatures by synchrotron $X$-ray powder diffraction at beamline 16-IDB of the Advanced Photon Source, Argonne National Laboratory. The X-ray beam size was $4.2 \times 5.3 \mu \mathrm{m}^{2}$ with a wavelength of $0.4066 \AA$. For laser heating, the diameter of a laser heating spot was up to $\sim 40 \mu \mathrm{m}$ at $\sim 1900 \mathrm{~K}$ in the flat top area created with two focused ytterbium fiber lasers from both sides of the sample that minimized both radial and axial temperature gradients. Temperatures were determined by fitting the thermal radiation from the central portion of the heated sample to the Planck radiation function [30]. About 2 wt.\% Au powder was added to the mixture for infrared laser absorption in the laser-heating experiment. Pressures were determined before and after heating by the self-consistent equation of states (EOS) of the doped $\mathrm{Au}$ [31], and the error bar of calibrated pressure is estimated to be of the order 1 to $2 \mathrm{GPa}$.

\section{Results}

We first performed structure predictions containing up to four formula units (f.u.) in the simulation cell over a wide range of pressures (0, 100, and $200 \mathrm{GPa})$. At ambient pressure, we found that the most stable structure was the $R-3 c$ phase, in agreement with the previous experiments [18]. At both 100 and $200 \mathrm{GPa}$, we uncovered a group of new structures, indicating potential new phases induced by pressure. Among them, the tetragonal $P_{4}{ }_{2}{ }_{1} 2$ structure was found to be the most stable at $200 \mathrm{GPa}$. The calculated enthalpy curves (relative to the $R-3 c$ structure, Figure $1 \mathrm{a}$ ) illustrate the relative thermodynamic stabilities of the structures. Our results show that, up to $136 \mathrm{GPa}$, the ambient $R-3 c$ structure is the most stable one. Beyond $136 \mathrm{GPa}$ and up to $200 \mathrm{GPa}$, the predicted $P 4_{2} 2_{1} 2$ structure becomes more stable. The phase transition from the ambient $R-3 c$ to the tetragonal $P 4_{2} 2{ }_{1} 2$ involves rotation of $\mathrm{FeF}_{6}$ octahedrons. This enables the structure to pack closely and, consequently, results in larger volume reduction across the phase transition at high pressure. To further understand the effect 
of pressure, we also plotted the enthalpy components (internal energy term $U$ and pressure-volume, $p V$, terms) of the $P 4_{2} 2_{1} 2$ structure relative to the $R-3 c$ structure in Figure $1 \mathrm{a}$. The $R-3 c$ structure has the lowest internal energy over the entire pressure range calculated in this work. However, beyond $136 \mathrm{GPa}$, the enthalpy of the $P 4_{2} 2{ }_{1} 2$ structure becomes lower than that of the $R-3 c$ structure. The main contribution to the enthalpy at high pressure is the $p V$ term. At $136 \mathrm{GPa}$, the relative volume reduction of the $P 4_{2} 2_{1} 2$ structure is $1.6 \%$ per formula unit, becoming large enough to compensate for the internal energy difference. The dynamic stabilities of the newly predicted $P 4_{2} 2_{1} 2$ structure was examined by calculating the phonon spectra using the supercell method. No imaginary phonon frequencies were found in the whole Brillouin zone over the studied pressure range, establishing the dynamical stability of the $P 4_{2} 2_{1} 2$ structure (Figure $1 \mathrm{~b}$ ).
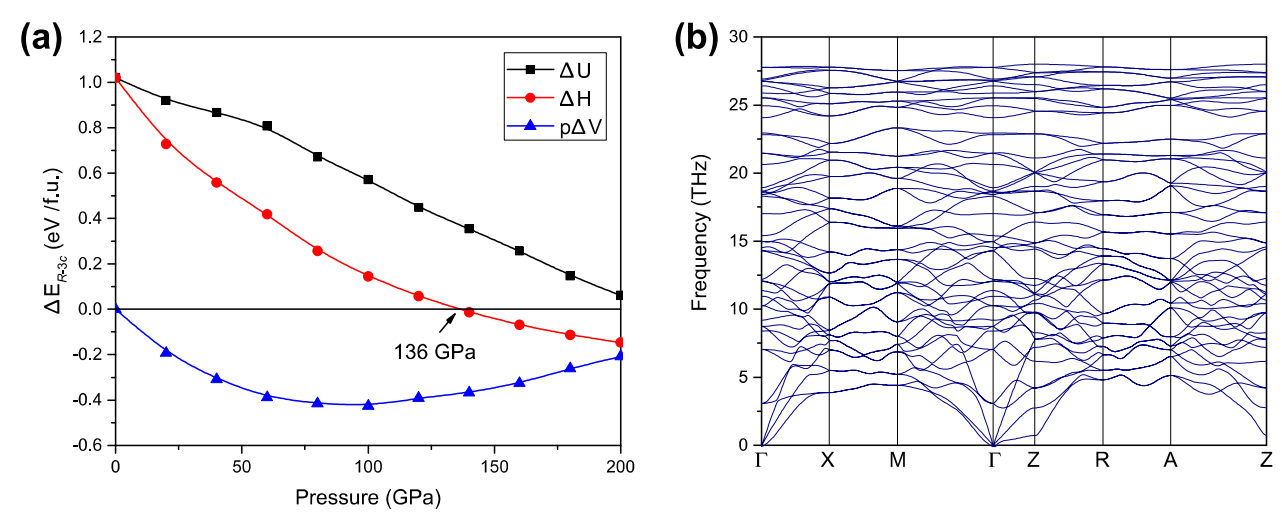

Figure 1. Enthalpy curves and phonon dispersion of the $P 4_{2} 212$ structure. (a) The difference in enthalpy, internal energy $U$, and the $p V$ term between the $P 4_{2}{ }_{2}{ }_{2}$ structure and the $R-3 c$ structure per formula unit as a function of pressure. (b) Calculated phonon dispersion of the $P 4_{2} 2{ }_{1} 2$ structure at $140 \mathrm{GPa}$.

We then conducted high-pressure experiments in search of the simulated structure. The mixture of the amorphous $\mathrm{FeF}_{3}$ and $\mathrm{Au}$ powder was first compressed to $78 \mathrm{GPa}$ at room temperature with $\mathrm{Au}$ as an internal pressure standard [31]. The sample was then heated using a double-sided laser system and held at target temperatures for $\sim 10 \mathrm{~min}$ at $\sim 1900 \mathrm{~K}$. At $78 \mathrm{GPa}$ and $1900 \mathrm{~K}$, we observed the formation of the predicted tetragonal $P 4_{2} 2{ }_{1} 2$ phase. The sample was subsequently compressed to $130 \mathrm{GPa}$ at room temperature in nine pressure steps (Table 1). At each pressure step, the sample was annealed for $10 \mathrm{~min}$ at $\sim 1800 \mathrm{~K}$, and in situ X-ray diffraction (XRD) spectra were acquired before and after the annealing. The diffraction data show that the tetragonal $P 4_{2} 2_{1} 2$ phase was stable in the pressure range from 78 to $130 \mathrm{GPa}$ and up to $1800 \mathrm{~K}$. It is worth mentioning that our experimental temperatures were lower than an average geotherm of the lowermost mantle, although they were closer to that of the cold slab subduction regions [32]. In Figure 2, we show an XRD pattern collected at 119 GPa after laser heating to $1800 \mathrm{~K}$. All peaks indexed to the calculated tetragonal unit cell are assigned in the XRD pattern with a few minor peaks indexed to a pyrite-type $\mathrm{FeF}_{2}$ (Figure 2), which is also a stable structure based on our calculation. The minor pyrite- $\mathrm{FeF}_{2}$ phase could be formed by releasing $\mathrm{F}$ from $\mathrm{FeF}_{3}$ under high temperature or due to the lack of $\mathrm{F}$ in the starting composition. Unit cell parameters of the tetragonal $P 4_{2} 2_{1} 2$ phase acquired at $300 \mathrm{~K}$ from 78-130 GPa are summarized in Table 1 , and the PV data are plotted in Figure 3. We fit the PV data to the third-order Birch-Murnaghan equation of state:

$$
P(V)=\frac{3 K_{0}}{2}\left[\left(\frac{V_{0}}{V}\right)^{\frac{7}{3}}-\left(\frac{V_{0}}{V}\right)^{\frac{5}{3}}\right]\left\{1+\frac{3}{4}\left(K_{0}^{\prime}-4\right)\left[\left(\frac{V_{0}}{V}\right)^{\frac{2}{3}}-1\right]\right\}
$$

and determined $K_{0}=109(10) \mathrm{GPa}$ and $K_{0^{\prime}}=3.9(2)$. The tetragonal $\mathrm{P}_{2}{ }_{2}{ }_{1} 2$ phase of $\mathrm{FeF}_{3}$ is more compressible than iron and iron hydrides [33] but less than $\mathrm{FeH}_{5}$ [34]. We also calculated the equation of state of the tetragonal $\mathrm{FeF}_{3}$, and listed the result in Table 2 from the first-principles simulation and plotted in Figure 3 together with the experimentally measured data for comparison. 
Table 1. Lattice parameters of tetragonal $\mathrm{FeF}_{3}$ up to $130 \mathrm{GPa}$ and $1900 \mathrm{~K}$.

\begin{tabular}{ccccc}
\hline $\boldsymbol{P}(\mathrm{GPa})$ & $\boldsymbol{a}(\AA)$ & $\boldsymbol{c}(\AA)$ & $\boldsymbol{V} /\left(\AA^{\mathbf{3}} / \mathbf{f} . \mathbf{u}.\right)$ & Density $\left(\mathrm{g} / \mathrm{cm}^{\mathbf{3}}\right)$ \\
\hline 78 & $4.010(2)$ & $6.992(2)$ & $28.11(2)$ & $6.501(5)$ \\
81 & $3.993(2)$ & $6.980(2)$ & $27.83(3)$ & $6.567(7)$ \\
90 & $3.983(2)$ & $6.939(4)$ & $27.52(2)$ & $6.639(5)$ \\
98 & $3.949(2)$ & $6.896(3)$ & $26.88(2)$ & $6.799(5)$ \\
106 & $3.919(1)$ & $6.836(4)$ & $26.25(2)$ & $6.962(5)$ \\
110 & $3.910(1)$ & $6.806(4)$ & $26.01(2)$ & $7.026(5)$ \\
118 & $3.905(1)$ & $6.778(3)$ & $25.84(2)$ & $7.072(6)$ \\
122 & $3.884(1)$ & $6.765(4)$ & $25.69(2)$ & $7.113(6)$ \\
126 & $3.878(1)$ & $6.756(4)$ & $25.40(2)$ & $7.193(6)$ \\
130 & $3.854(1)$ & $6.725(4)$ & $24.98(2)$ & $7.316(6)$ \\
\hline
\end{tabular}

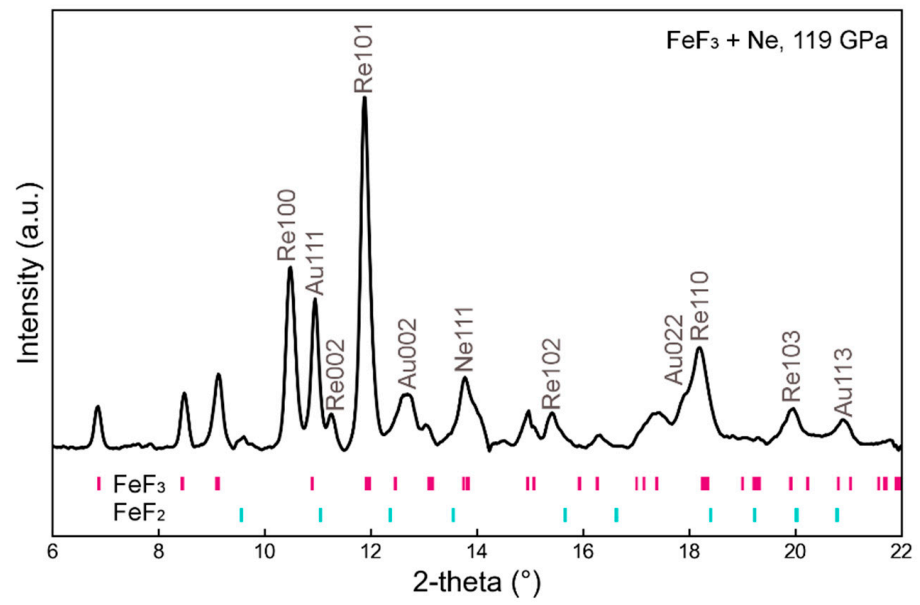

Figure 2. X-ray diffraction patterns at $119 \mathrm{GPa}$ (Au pressure), $300 \mathrm{~K}$ after laser heating. At the center of the heated area, the majority of diffraction peaks (other than those from Au and Re) belong to the tetragonal $\mathrm{P}_{2} 2_{1} 2$ phase of $\mathrm{FeF}_{3}$. A few minor peaks are consistent with the pyrite-type $\mathrm{FeF}_{2}$. Data were acquired using an X-ray wavelength of $0.4066 \AA$.

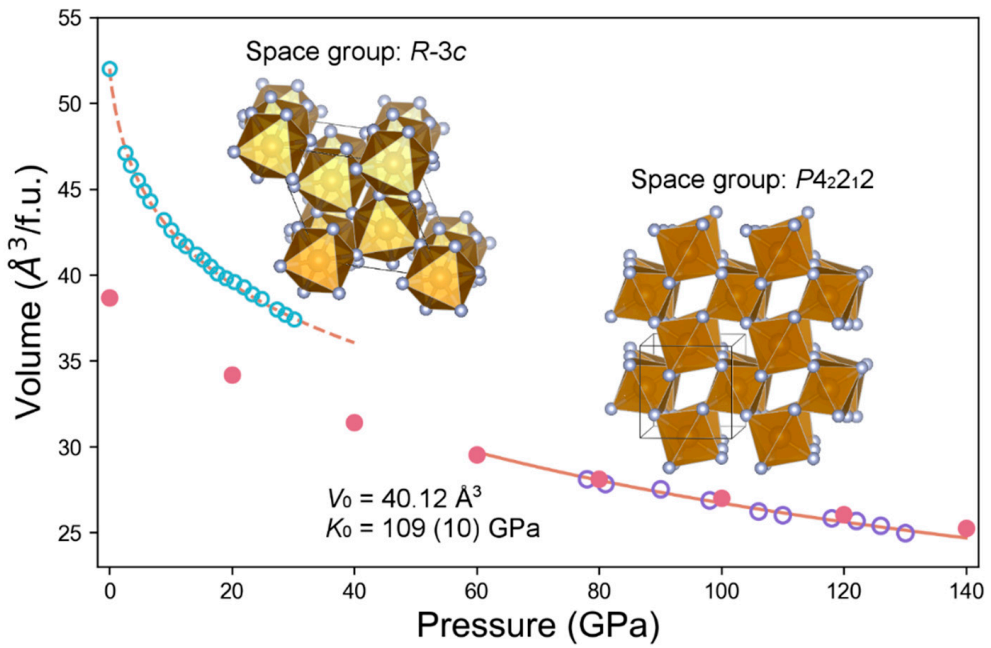

Figure 3. Measured $\mathrm{FeF}_{3}$ unit cell volumes at high pressure and $300 \mathrm{~K}$. Open purple circles from this study show pressures based on the Au pressure calibration (the error bar of $\pm 2 \mathrm{GPa}$ ). The solid curve at relatively high pressures from 78 to $130 \mathrm{GPa}$ shows the equation of state for $\mathrm{FeF}_{3}$ with a tetragonal unit-cell structure. Solid red circles are calculated by first-principles simulation. The equation of state of high-pressure tetragonal $\mathrm{FeF}_{3}$ is compared with the low-pressure trigonal phase [18]. 
Table 2. Lattice parameters of tetragonal $\mathrm{FeF}_{3}$ from first-principles simulation.

\begin{tabular}{ccccc}
\hline $\boldsymbol{P}(\mathbf{G P a})$ & $\boldsymbol{a}(\AA)$ & $\boldsymbol{c}(\AA)$ & $\boldsymbol{V}\left(\AA^{\mathbf{3}} / \mathbf{f} . \mathbf{u}.\right)$ & Density $\mathbf{( g / \mathbf { c m } ^ { 3 } )}$ \\
\hline 0 & 4.435 & 7.867 & 38.68 & 4.853 \\
20 & 4.290 & 7.425 & 34.17 & 5.493 \\
40 & 4.205 & 7.104 & 31.40 & 5.978 \\
60 & 4.138 & 6.901 & 29.54 & 6.354 \\
80 & 4.083 & 6.747 & 28.12 & 6.675 \\
100 & 4.037 & 6.625 & 26.99 & 6.955 \\
120 & 3.996 & 6.527 & 26.06 & 7.203 \\
140 & 3.961 & 6.442 & 25.26 & 7.431 \\
\hline
\end{tabular}

\section{Discussion}

Recent synthesis experiments showed that Al-bearing bridgmanite under the conditions of the uppermost lower mantle can contain up to $\sim 1.3 \mathrm{wt} . \% \mathrm{~F}$ [12], which is much higher than in the other oxide minerals, such as $\sim 5100 \mathrm{ppm}$ in olivine [7-9], $\sim 660 \mathrm{ppm}$ in pyroxenes [10,11], and $\sim 1100 \mathrm{ppm}$ in pyrope [8] and $\sim 2110 \mathrm{ppm}$ in wadsleyite [11]. The concentrations of $\mathrm{F}$ incorporated in oxide minerals can be affected by water contents due to the similar charge and comparable ionic radius of $\mathrm{F}^{-}$and $\mathrm{OH}^{-}[35,36]$. That is, the presence of $\mathrm{F}$ may play a similar role as water in impacting the mineralogy of the deep mantle and the distribution of water in the Earth's interior [37-42]. Our experimental results show that the dense $\mathrm{FeF}_{3}\left(\sim 6.5-7.3 \mathrm{~g} / \mathrm{cm}^{3}\right.$, see Table 1) with a tetragonal unit-cell structure is gravitationally stable at the bottom of the lower mantle and indicate that it can be a potential $\mathrm{F}$ reservoir at such depths. This further supports the speculation of an F-enriched source region in the Earth's interior $[4,5,12]$ and that may explain the phenomenon of the content of $F$ being much lower than other elements with similar atomic numbers [6]. To better constrain distribution of $\mathrm{F}$ and other halogens in the BSE, however, required more dedicated high pressure-temperature experiments along average mantle geotherm conditions, such as $\mathrm{F}$ partitioning between $\mathrm{FeF}_{3}$ and oxide minerals, its crystal chemistry, and the stabilities of other halogenides [15].

Author Contributions: Y.L. and Q.H. designed the research; Y.L., Q.H., and Y.M. performed experiments; Q.H. and Y.L. analyzed data; L.Z. did the model calculation; and Y.L. and Q.H. wrote the paper with input from all authors. All authors have read and agreed to the published version of the manuscript.

Funding: Y.L. is supported by NSF Grants EAR-1722515. Q.H. is supported by NSFC (No.17N1051-0213). HPCAT operations are supported by DOE-NNSA's Office of Experimental Sciences. APS is supported by DOE-BES, under contract no. DE-AC02-06CH11357. Computations were supported by Carnegie computational resources. The Center for High Pressure Science and Technology Advanced Research is supported by NSAF (Grants U1530402 and U1930401).

Acknowledgments: This work was performed at HPCAT (Sector 16), Advanced Photon Source (APS), Argonne National Laboratory. HPCAT operations are supported by DOE-NNSA's Office of Experimental Sciences. The Advanced Photon Source is a U.S. Department of Energy (DOE) Office of Science User Facility operated for the DOE Office of Science by Argonne National Laboratory.

Conflicts of Interest: The authors declare no conflict of interest.

\section{References}

1. McDonough, W.F.; Sun, S. The composition of the Earth. Chem. Geol. 1995, 120, 223-253. [CrossRef]

2. Dingwell, D.B.; Mysen, B.O. Effects of water and fluorine on the viscosity of albite melt at high pressure: A preliminary investigation. Earth Planet. Sci. Lett. 1985, 74, 266-274. [CrossRef]

3. Filiberto, J.; Wood, J.; Dasgupta, R.; Shimizu, N.; Le, L.; Treiman, A.H. Effect of fluorine on near-liquidus phase equilibria of a Fe-Mg rich basalt. Chem. Geol. 2012, 312, 118-126. [CrossRef]

4. Kovalenko, V.; Naumov, V.; Girnis, A.; Dorofeeva, V.; Yarmolyuk, V. Composition and chemical structure of oceanic mantle plumes. Petrology 2006, 14, 452-476. [CrossRef] 
5. Joachim, B.; Stechern, A.; Ludwig, T.; Konzetti, J.; Pawley, A.; Ruzié, L.; Burgess, R.; Ballentine, C.J. Effect of water on the fluorine and chlorine partitioning behavior between olivine and silicate melts. Contrib. Mineral. Petrol. 2017, 172, 15. [CrossRef]

6. Koga, K.T.; Rose-Koga, E.F. Fluorine in the Earth and the solar system, where does it come from and can it be found? C. R. Chimie 2018, 21, 749-756. [CrossRef]

7. Bromiley, D.W.; Kohn, S.C. Comparisons between fluoride and hydroxide incorporation in nominally anhydrous and fluorine-free mantle minerals. Geochim. Cosmochim. Acta 2007, 71, A124.

8. Bernini, D.; Wiedenbeck, M.; Dolejš, D.; Keppler, H. Partitioning of halogens between mantle minerals and aqueous fluids: Implications for the fluid flow regime in subduction zones. Contrib. Mineral. Petrol. 2012, 165, 117-128. [CrossRef]

9. Gruützner, T.; Klemme, S.; Rohrbach, A.; Gervasoni, F.; Berndt, J. The role of F-clinohumite in volatile recycling processes in subduction zones. Geology 2017, 45, 443-446. [CrossRef]

10. Dalou, C.; Koga, K.T.; Shimizu, N.; Boulon, J.; Devidal, J.-L. Experimental determination of $\mathrm{F}$ and $\mathrm{Cl}$ partitioning between lherzolite and basaltic melt. Contrib. Mineral. Petrol. 2012, 163, 591-609. [CrossRef]

11. Gruützner, T.; Klemme, S.; Rohrbach, A.; Gervasoni, F.; Berndt, J. The effect of fluorine on the stability of wadsleyite: Implications for the nature and depths of the transition zone in the Earth's mantle. Earth Planet. Sci. Lett. 2018, 482, 236-244.

12. Yoshino, T.; Jaseem, V. Fluorine solubility in bridgmanite: A potential fluorine reservoir in the Earth's mantle. Earth Planet. Sci. Lett. 2018, 504, 106-114. [CrossRef]

13. Kaminsky, F.V.; Wirth, R.; Schreiber, A. Carbonatitic inclusions in Deep Mantle diamond from Juina, Brazil: New minerals in the carbonate-halide association. Can. Mineral. 2013, 51, 669-688. [CrossRef]

14. Kaminsky, F.V.; Ryabchikov, I.D.; Wirth, R. A primary natrocarbonatitic association in the Deep Earth. Miner. Petrol. 2016, 110, 387-398. [CrossRef]

15. Du, X.P.; Wang, Z.; Wang, H.; Iitaka, T.; Pan, Y.; Wang, H.; Tse, J.S. Structures and Stability of Iron Halides at the Earth's Mantle and Core Pressures: Implications for the Missing Halogen Paradox. ACS Earth Space Chem. 2018, 2, 711-719. [CrossRef]

16. Andrault, D.; Muñoz, M.; Pesce, G.; Cerantola, V.; Chumakov, A.; Kantor, I.; Pascarelli, S.; Rüffer, R.; Hennet, L. Large oxygen excess in the primitive mantle could be the source of the Great Oxygenation Event. Geochem. Perspect. Lett. 2018, 6, 5-10. [CrossRef]

17. Frost, D.J.; Mann, U.; Asahara, Y.; Rubie, D.C. The redox state of the mantle during and just after core formation. Philos. Trans. A. Math. Phys. Eng. Sci. 2008, 366, 4315-4337. [CrossRef]

18. Jørgensen, J.-E.; Staun Olsen, J.; Gerward, L. Compression mechanism of GaF3 and FeF 3 : A high-pressure X-ray diffraction study. High Press. Res. 2010, 30, 634-642. [CrossRef]

19. Wang, Y.; Lv, J.; Zhu, L.; Ma, Y. Crystal structure prediction via particle-swarm optimization. Phys. Rev. B 2010, 82, 94116. [CrossRef]

20. Wang, Y.; Lv, J.; Zhu, L.; Ma, Y. CALYPSO: A method for crystal structure prediction. Comput. Phys. Commun. 2012, 183, 2063-2070. [CrossRef]

21. Zhu, L.; Wang, Z.; Wang, Y.; Zou, G.; Mao, H.; Ma, Y. Spiral Chain O4 Form of Dense Oxygen. Proc. Natl. Acad. Sci. USA. 2012, 109, 751-753. [CrossRef] [PubMed]

22. Wang, Y.; Lv, J.; Zhu, L.; Lu, S.; Yin, K.; Li, Q.; Wang, H.; Zhang, L.; Ma, Y. Materials discovery via CALYPSO methodology. J. Phys. Condens. Matter. 2015, 27, 203203. [CrossRef] [PubMed]

23. Zhu, L.; Borstad, G.M.; Liu, H.; Guńka, P.A.; Guerette, M.; Dolyniuk, J.-A.; Meng, Y.; Greenberg, E.; Prakapenka, V.B.; Chaloux, B.L.; et al. Carbon-boron clathrates as a new class of $s p^{3}$-bonded framework materials. Sci. Adv. 2020, 6, eaay8361. [CrossRef] [PubMed]

24. Perdew, J.P.; Burke, K.; Ernzerhof, M. Generalized Gradient Approximation Made Simple. Phys. Rev. Lett. 1996, 77, 3865-3868. [CrossRef]

25. Kresse, G.; Furthmüller, J. Efficient iterative schemes for ab initio total-energy calculations using a plane-wave basis set. Phys. Rev. B 1996, 54, 11169-11186. [CrossRef] [PubMed]

26. Blöchl, P.E. Projector augmented-wave method. Phys. Rev. B 1994, 50, 17953-17979. [CrossRef]

27. Togo, A.; Tanaka, I. First principles phonon calculations in materials science. Scr. Mater. 2015, 108, 1-5. [CrossRef]

28. Jephcoat, A.P.; Mao, H.-K.; Bell, P.M. Hydrothermal Experiment Techniques, 1st ed.; Wiley-Interscience: Hoboken, NJ, USA, 1987. 
29. Meng, Y.; Hrubiak, R.; Rod, E.; Boehler, R.; Shen, G. New developments in laser-heated diamond anvil cell with in situ synchrotron x-ray diffraction at High Pressure Collaborative Access Team. Rev. Sci. Instrum. 2015, 86, 072201. [CrossRef]

30. Yuan, H.; Zhang, L. In situ determination of crystal structure and chemistry of minerals at Earth's deep lower mantle conditions. Matter Radiat. Extremes 2017, 2, 117-128. [CrossRef]

31. Fei, Y.; Ricolleau, A.; Frank, M.; Mibe, K.; Shen, G.; Prakapenka, V. Toward an internally consistent pressure scale. Proc. Natl. Acad. Sci. USA 2007, 104, 9182-9186. [CrossRef]

32. Nishi, M.; Irifune, T.; Tsuchiya, J.; Tange, Y.; Nishihara, Y.; Fujino, K.; Higo, Y. Stability of hydrous silicate at high pressures and water transport to the deep lower mantle. Nat. Geosci. 2014, 7, 224-227. [CrossRef]

33. Pépin, C.M.; Dewaele, A.; Geneste, G.; Loubeyre, P.; Mezouar, M. New Iron Hydrides under High Pressure. Phys. Rev. Lett. 2014, 113, 265504. [CrossRef] [PubMed]

34. Pépin, C.M.; Geneste, G.; Dewaele, A.; Mezouar, M.; Loubeyre, P. Synthesis of FeH 5 : A layered structure with atomic hydrogen slabs. Science 2017, 357, 382-385. [CrossRef] [PubMed]

35. Shannon, R.D. Revised effective ionic radii and systematic studies of interatomic distances in halides and chalcogenides. Acta Crystallogr. 1976, 32, 751-767. [CrossRef]

36. Hazen, R.M.; Yang, H.; Prewitt, C.T.; Gasparik, T. Crystal chemistry of superfluorous phase $B\left(\mathrm{Mg}_{10} \mathrm{Si}_{3} \mathrm{O}_{1} 4 \mathrm{~F}_{4}\right)$, implications for the role of fluorine in the mantle. Am. Mineral. 1997, 82, 647-650. [CrossRef]

37. Zhu, S.-C.; Hu, Q.; Mao, W.L.; Mao, H.-K.; Sheng, H. Hydrogen-bond symmetrization breakdown and dehydrogenation mechanism of $\mathrm{FeO}_{2} \mathrm{H}$ at high pressure. J. Am. Chem. Sci. 2017, 139, 12129-12132. [CrossRef]

38. Lin, Y.; Hu, Q.; Meng, Y.; Walter, M.; Mao, H.-K. Evidence for the stability of ultrahydrous stishovite in Earth's lower mantle. Proc. Nat. Acad. Sci. USA 2020, 117, 184-189. [CrossRef]

39. Hu, Q.; Kim, D.Y.; Yang, W.; Yang, L.; Meng, Y.; Zhang, L.; Mao, H.-K. FeO 2 and FeOOH under deep lower-mantle conditions and Earth's oxygen-hydrogen cycles. Nature 2016, 534, 241-244. [CrossRef]

40. Hu, Q.; Liu, J.; Chen, J.; Yan, B.; Meng, Y.; Prakapenka, V.B.; Mao, W.L.; Mao, H.-K. Mineralogy of the deep lower mantle in the presence of $\mathrm{H}_{2} \mathrm{O}$. Natl. Sci. Rev. 2020. [CrossRef]

41. Mao, H.-K.; Mao, W.L. Key problems of the four-dimensional Earth system. Matter Radiat. Extremes 2020, 5, 038102. [CrossRef]

42. Kaminsky, F.V. Water in the Earth's lower mantle. Geochem. Int. 2018, 56, 1117-1134. [CrossRef] 